\title{
Analgesic activity of a polysaccharide in experimental osteoarthritis in rats
}

\section{Rondinelle Ribeiro Castro • \\ Judith Pessoa Andrade Feitosa • \\ Pablyana Leila Rodrigues da Cunha • \\ Francisco Airton Castro da Rocha}

Published online: 8 March 2007

(C) Clinical Rheumatology 2007

The legend of the $y$-axis in Fig. 2 should read "PET (s/1 min)".

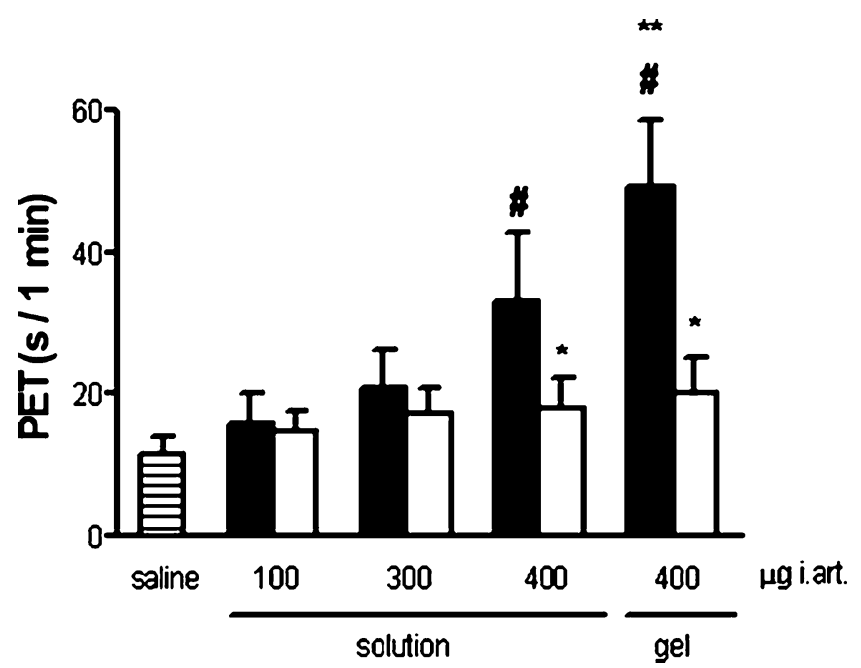

Fig. 2 Joint pain provoked by intraarticular (i.a.) administration of guar gum (GG) into rat joints. Nonpurified (filled bars) and purified (open bars) GG $(100-400 \mu \mathrm{g} / 50 \mu \mathrm{l})$ solution or gel $(400 \mu \mathrm{g} / 50 \mu \mathrm{l})$, were given i.a. Control (hatched bar) received saline i.a. The joint pain was measured using the articular incapacitation test for rats (see text for details). Values represent the maximal value of the paw elevation time (PET) recorded after injection of the compounds. Maximal PET occurred between 3 and $4 \mathrm{~h}$ after i.a. injection. Results

The online version of the original article can be found at http://dx.doi. are expressed as the mean $\pm \mathrm{SD}$ of groups of six animals. ${ }^{\#} p<0.001 \mathrm{vs}$ saline; ${ }^{*} p<0.01$ vs nonpurified GG at the same dose; ${ }^{\S} p<0.001$ vs org/10.1007/s10067-006-0506-9.

\section{R. R. Castro} $400 \mu \mathrm{g}$ nonpurified GG solution (one-way ANOVA followed by

Department of Physiology and Pharmacology, Tukey's test)

Federal University of Ceará,

Fortaleza, Ceara, Brazil

\section{J. P. A. Feitosa • P. L. R. da Cunha}

Department of Organic and Inorganic Chemistry,

Federal University of Ceará,

Fortaleza, Ceara, Brazil

F. A. C. da Rocha $(\bowtie)$

Department of Internal Medicine, Federal University of Ceará,

Fortaleza, Ceara, Brazil

e-mail: arocha@ufc.br 